\title{
Redesigning First Year Anatomy and Physiology Subjects for Allied Health Students: Impact of Active Learning Strategies
}

\author{
Monika A. Zimanyi ${ }^{\mathrm{a}}$, Nick F. Emtage ${ }^{\mathrm{b}}$ and Pam Megaw ${ }^{\mathrm{c}}$ \\ Corresponding author: Monika A. Zimanyi, monika.zimanyi@jcu.edu.au \\ ${ }^{a}$ Discipline of Anatomy and Pathology, College of Medicine and Dentistry, James Cook University, Townsville \\ QLD 4810, Australia \\ ${ }^{\mathrm{b}}$ Planning, Performance and Analytics Directorate, James Cook University, Townsville QLD 4810, Australia \\ ${ }^{c}$ Biomedicine, College of Public Health, Medical and Veterinary Science, James Cook University, Townsville \\ QLD 4810, Australia
}

Keywords: active learning, student engagement, academic performance

\begin{abstract}
To combat high failure rates in an Anatomy and Physiology for first year Occupational Therapy, Physiotherapy and Sport Science students, a flipped classroom was introduced in 2015. It became apparent that students did not engage with materials prior to classes, but they did engage with in-class active learning strategies. In subsequent years of this study, our focus changed to delivery with student active learning in mind. The active learning approaches introduced resulted in improvements in academic performance for all three student cohorts. Occupational Therapy students' marks improved by $12.9 \%$ when comparing pre-intervention (2014) results to the end of the post-intervention period (2017), Physiotherapy students' marks increased by $6.9 \%$, while the greatest gains of $14.8 \%$ were seen in Sport Science students. When investigating the relationship between student performance and university entrance scores, students with high entrance scores demonstrated modest gains in performance, while those students with lower entrance scores benefited the most. Our results suggest that the introduction of active learning may result in the transition of the learning style of students under-prepared for university studies, to be more like those of more successful students; that is, to a deeper level of learning.
\end{abstract}

\section{Introduction}

Academic student diversity has led to a requirement for traditional teaching methods to be updated if students are to succeed. We previously described the delivery of flipped classroom activities to the physiology component of a first semester, first year, anatomy and physiology subject for allied health students (Megaw \& Zimanyi, 2019). Here, we describe the second semester, first year, anatomy and physiology subject, where the entire subject was delivered initially as a flipped classroom, then with a focus on active learning strategies. We were specifically interested in the effect of active learning on academic performance.

Prior to our intervention, anatomy and physiology was delivered to first year allied health students studying Occupational Therapy, Physiotherapy and Sport Science using a traditional didactic delivery, comprising of 3 x 50-minute lectures and a 2 hour practical class each week. Lectures were delivered to all of the allied health students in one sitting but the practical classes were delivered separately to each discipline. The student diversity was illustrated by broad university entrance scores, and a high proportion of first-in-family students (Megaw \& Zimanyi, 2019). 
The second semester subject historically showed low success rates, which were even more marked than the poor success rates in the first semester subject. Failure rates in 2014 were $11.8 \%$ in the Physiotherapy cohort, $44 \%$ in the Occupational Therapy cohort and $54.5 \%$ in the Sport Science cohort. This impacted both student progression through their study programmes and contributed to poor student retention. We decided that to improve student performance, a change in curriculum delivery was necessary. In 2015, we revitalised the learning objectives, developed and implemented student-centred active learning techniques and introduced novel assessments. In this paper we describe an active learning strategy introduced, in the form of a flipped classroom, to combat surface learning, which is well known to result in poor student outcomes (Biggs, 1999). The new strategy promoted deep learning, in which new content delivered would be integrated by students leading to better understanding of subject matter (Ramsden, 1985). What we had hoped to achieve is eloquently described by Biggs (1999), to close the gap between the non-academic (less-well prepared) and academic (well prepared) student outcomes, by increasing students' level of engagement in their own learning, by way of increasing active learning strategies.

Student success is partially determined by their experiences during the first year of their degrees (Upcraft, Gardner \& Barefoot, 2005), so we designed learning experiences, which were studentfocussed (Weinstein, Madan and Sumeracki, 2018). In consultation with an educational designer, we designed the flipped classroom using the 5E's enquiry framework based on the principle that students learn and retain knowledge when they have had the opportunity to discover through different experiences (Bybee et al., 2006). In essence, what was delivered in the past in didactic lectures were now delivered as multiple short videos, each usually 15 minutes or less in duration. We designed materials with the aim of enabling our diverse students to engage with learning materials prior to their first face to face interactive sessions, via our learning management system (LMS). To further promote engagement, group tasks were implemented during the 50 minute interactive sessions, which replaced the didactic lectures. The interactive sessions enabled us to gauge student understanding of concepts, and to identify those concepts, which required further clarification. The tasks we assigned to students also promoted collaboration and socialisation within the student cohorts; a vital activity for students transitioning into university (Kift, 2010). To ease students into this new type of learning, we flipped the classroom for 4 weeks of semester one, covering the physiology content exclusively (Megaw \& Zimanyi, 2019) and then flipped the entire subject in second semester, covering both the anatomy and physiology content, the focus of this study.

\section{Strategies for active learning in a flipped classroom paradigm}

With the introduction of a flipped classroom, we provided suggested readings, and focus questions. The focus questions were questions that unpacked the learning objectives of that week. We created in house videos, as well as directed students to YouTube clips and provided online quizzes on our LMS to allow students to test their knowledge and understanding. We asked students to engage with the above-mentioned materials outside of class time, prior to the interactive sessions. Interactive sessions included all three rehabilitation science disciplines in a 50 minute group-based tasks, which utilised an audience response system (Turning Point $(\mathrm{OH}$, USA) or Gosoapbox (IL, USA)) and/or other paper-based activities (for instance crossword puzzles) for students to complete individually or in small groups. The academic provided adequate time for the activities, then provided answers to students and further explanation when required in the form of a minilecture, in response to students' lack of understanding demonstrated in these activities or through questions asked. It came to light through LMS analytics that students were not engaged with the pre-class activities in 2015, but were 
obviously actively involved in the learning activities in the interactive session and practical/workshop classes. We therefore shifted focus away from the flipped classroom, made further improvements to the learning activities and eliminated the need for student engagement prior to attending interactive sessions.

We also introduced changes to the way we ran the anatomy practical classes. Students explored a multitude of materials including cadavers, dissections, models and x-ray images, in order to learn morphology and important spatial relationships between structures in the allocated 2 hours, as separate cohorts. Students in the past had been given a checklist of tasks to complete and during the practical class, they engaged with all of the materials available, at their own pace, to meet the learning objectives. Students who were poorly prepared for university often struggled with time management and failed to complete all of the tasks when left to their own devices. To counteract this, the anatomy practical sessions were restructured to ensure that all students were able to access all of the learning materials provided in the allocated time. This was achieved by organising 'stations', with each station supervised by an instructor. Groups of students rotated between stations over the course of the practical class to ensure that all students had the opportunity to interact with all the materials made available, and were adequately supported at each station. A workbook was prepared and posted on the LMS, containing activities including crosswords, labelling of images and fill in the blanks, to allow students to test their knowledge. Students were encouraged to bring their workbooks to practical classes so they could discuss areas of uncertainty with their instructor at a station specifically designated for this activity.

Physiology workshops were also of 2 hour duration, with individual cohorts having separate classes. Group based activities were introduced in place of practical classes, which in the past often involved individual workbook exercises. These included newly developed small group activities such as role plays, simulations and case studies (for more detail see Megaw \& Zimanyi, 2019), which enabled students to explore threshold concepts in detail and promoted deep learning, while working in a semi-social setting. Group-based activities presented in the first year of studies assisted students in making friends, it presented opportunities for students to experience active, collaborative, cooperative and problem based learning, which have been shown to improve student attitudes to and motivation for learning; as well as enhancing thinking and retention of information (Prince, 2004).

In addition to revising content delivery, we reviewed the assessments and made adjustments to better align them with the changes implemented with the flipped classroom. Prior to our intervention, students performed weekly tests comprising of 10 multiple choice questions (MCQ) as a hurdle requirement, to encourage students to engage in the subject on a weekly basis. The on-course summative assessment was administered as 4 semester tests including 20 MCQs covering 3 weeks of material each. Students were further assessed by completing endof-semester invigilated theory and practical examinations. In 2015, the on-course assessment was transformed into a single weekly test with 10 questions, which were completed in the last 10 minutes of their practical or workshop classes and contributed to their final end of semester mark. As previously, practical and theory examinations were administered to students at the end of semester containing the same number of questions and given the same time to complete it. In this study, we compare results of the students' weekly tests, practical and theory examinations, as well as their overall marks in 2014, prior to intervention, to students' results in 2015 after the introduction of the flipped classroom. 
In addition to on course tests, in 2016 and 2017, the assessment weighting was also changed and a new assessment item - a digital explanation (DigiExplanations@; Hoban, Nielsen \& Shepherd, 2013) - was added to the curriculum (Table 1). The DigiExplanations assessment item required groups of 4 or 5 students to prepare a video explaining a topic related to material covered in the subject. Its inclusion would reduce the emphasis on the end of semester examinations, promote multimodal communication and allow students more opportunities to collaborate and assimilate concepts. We report on the introduction of the DigiExplanations in a future manuscript. We make further comparisons between student outcomes of the flipped classroom pedagogy in 2015 and the subsequent 2 years of active learning delivery.

Table 1. Subject parameters over the course of the study (2014 to 2017) and the introduction of a new assessment item, DigiExplanations, in 2016; an assessment item that utilises active learning.

\begin{tabular}{|l|c|c|c|c|}
\hline & $\mathbf{2 0 1 4}$ & $\mathbf{2 0 1 5}$ & $\mathbf{2 0 1 6}$ & $\mathbf{2 0 1 7}$ \\
\hline Class sizes & 276 & 257 & 208 & 192 \\
\hline & & & & \\
\hline \multicolumn{1}{|c|}{ Occupational Therapy } & 108 & 71 & 75 & 68 \\
\hline \multicolumn{1}{|c|}{ Physiotherapy } & 69 & 73 & 53 & 76 \\
\hline \multicolumn{1}{|c|}{ Sport Science } & 99 & 113 & 80 & 48 \\
\hline Contact (hours/week) & 5 & 3 & 3 & 3 \\
\hline & & & & \\
\hline On course & $30 \%$ & $30 \%$ & $30 \%$ & $30 \%$ \\
\hline Practical Examinations & $30 \%$ & $30 \%$ & $25 \%$ & $25 \%$ \\
\hline Theory Examinations & $40 \%$ & $40 \%$ & $25 \%$ & $25 \%$ \\
\hline DigiExplanations@ & & & $20 \%$ & $20 \%$ \\
\hline
\end{tabular}

At the end of semester, two invigilated assessment items were administered to determine student success in meeting the learning objectives: a practical and a theory examination.

\section{Data Analyses}

For each of the three cohorts, the mean mark for each assessment item and the overall mark, was analysed using a one-way analysis of variance (ANOVA). Post-hoc comparisons were made using a Tukey Honest Significant Difference (HSD) test and significance was accepted at $\mathrm{p}<$ 0.05 . Results are presented as mean \pm Standard Error of the Mean (SEM).

A Chi-square Automatic Interaction Detector (CHAID) test was used to examine the relationship between the different variables (e.g. entry scores, year of study, age of students). This process utilises two-sided t-tests, assuming equal variances adjusted for all pairwise comparisons within a row of each innermost sub-table using the Bonferroni correction. All analyses were carried out using IBM SPSS Statistics for Windows (Version 25.0; NY, USA).

Ethics approval for this project was awarded from James Cook University Human Ethics Committee under approval number H6099. 


\section{So what was the effect on academic outcomes?}

Introduction of the flipped classroom in 2015 resulted in improvements in academic performance indicators, particularly of students that were historically the least well prepared for tertiary study in our first year Anatomy and Physiology allied health subjects.

\section{The On-course Tests}

On-course test results significantly improved for all 3 student cohorts with the introduction of the flipped classroom approach (Figure 1). Compared to 2014 (pre-intervention), there was an increase in marks of $8.2 \%$ for Occupational Therapy students $(\mathrm{p}<0.001), 10.5 \%$ for the Physiotherapy $(\mathrm{p}<0.0001)$ and $7.8 \%(\mathrm{p}<0.001)$ for Sport Science students in 2015. The improvements seen in 2015 were maintained in 2016 and 2017 with the introduction of refined active learning approaches.

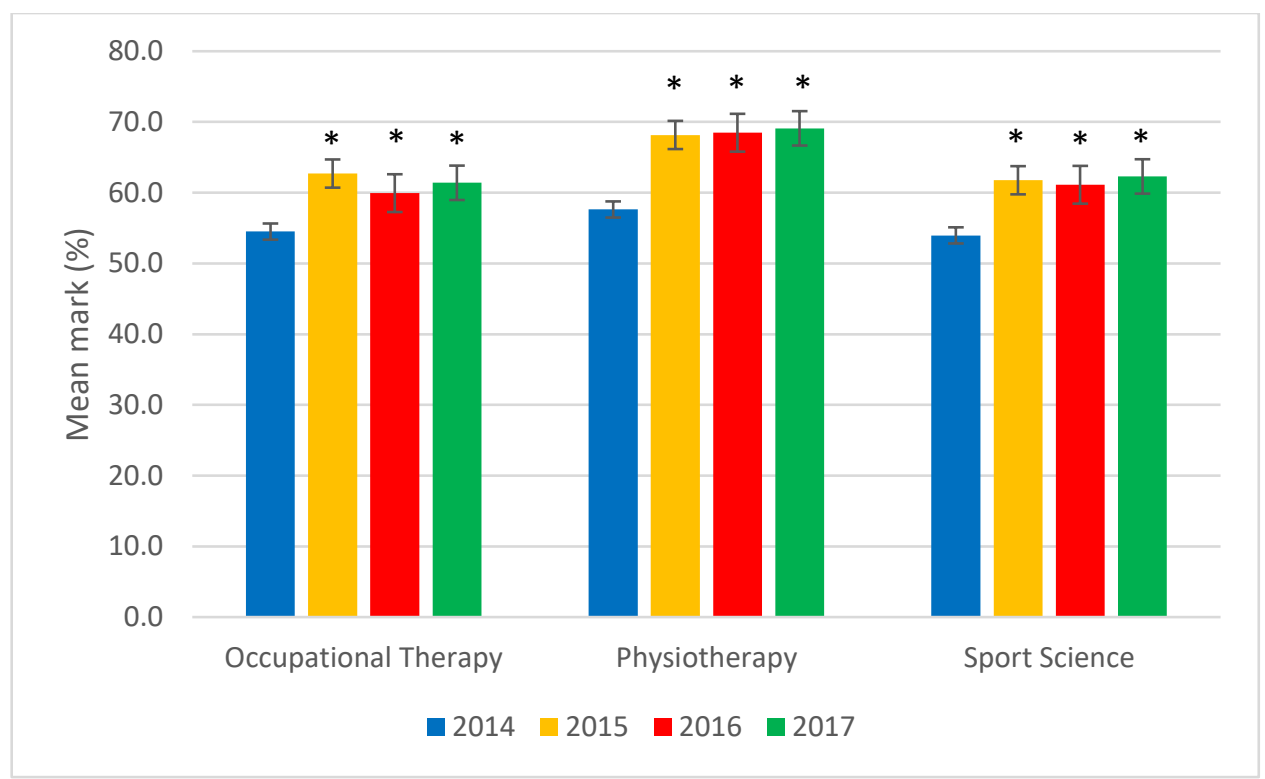

Figure 1. On-course Test Marks

The mean on-course test marks for the Occupational Therapy, Physiotherapy and Sport Science cohorts in 2014 (pre-intervention) were significantly lower than in 2015 with the introduction of flipped classroom pedagogy, but no further improvements were observed with the introduction of further active learning approaches. ${ }^{*} p<0.05$, when compared to 2014 values.

\section{The Practical Examination}

Students studying Occupational Therapy showed a highly significant $(\mathrm{p}<0.0001)$ improvement in their practical examination marks in 2015, the year that the flipped classroom was introduced (Figure 2). Practical examination marks in 2016 and 2017 were significantly reduced in subsequent years of this study when the active learning strategies were refined. Physiotherapy students' practical examination marks did not change, with the introduction of active learning strategies. The Sport Science students' results were significantly increased $(\mathrm{p}<0.0001)$ in 2015 when compared to 2014, which was maintained for the duration of the study $(\mathrm{p}<0.05)$. 


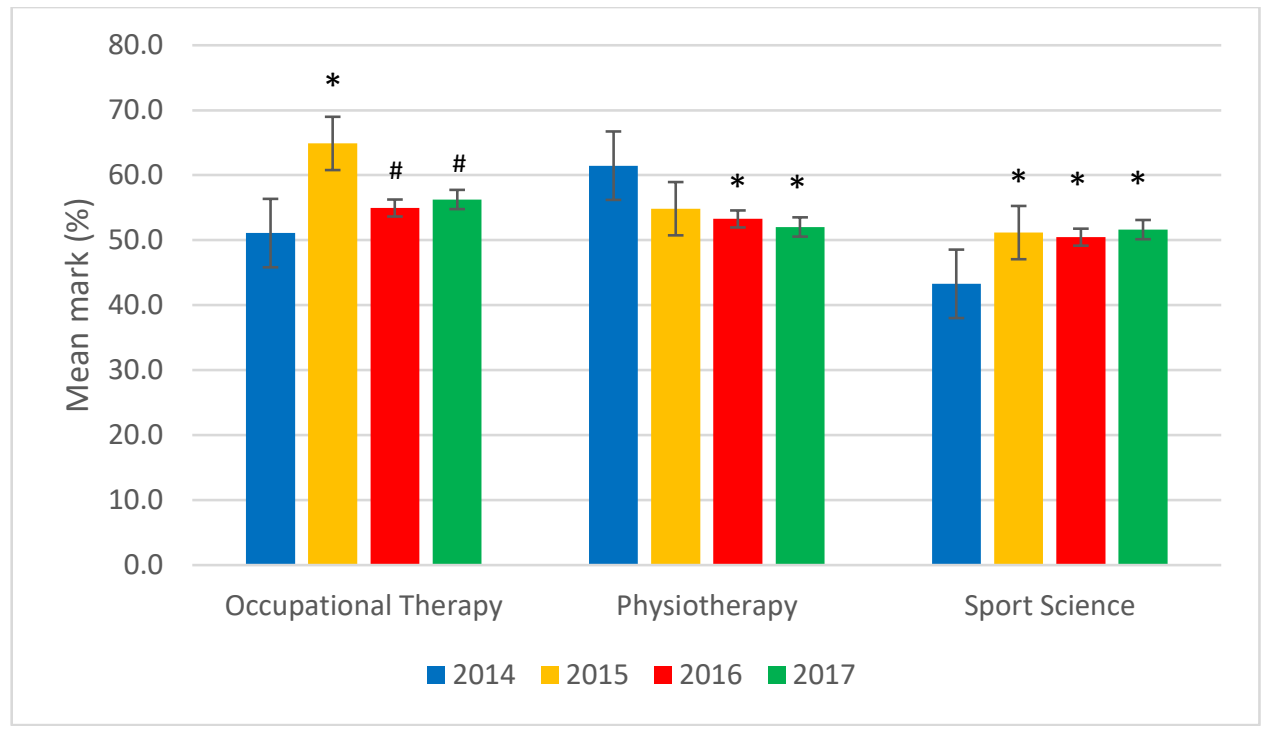

Figure 2. Practical Examination Marks

Occupational Therapy practical examination marks significantly increased in 2015 compared to 2014, but significantly decreased in 2016 and 2017 with the introduction of further active learning activities. There was no change in Physiotherapy practical examination marks in 2015 compared to 2014. The introduction of more active learning strategies in 2016 and 2017 did not have an impact on practical examination marks for physiotherapy students. Sport Science practical examination marks were significantly increased in 2015, compared to 2014 and this increase was sustained in 2016 and 2017 . * p $<0.05$ when compared to 2014 values; \# $p<0.05$ when compared to 2015 values.

\section{The Theory Examination}

Occupational Therapy theory examination marks (Figure 3) did not change in 2015 with the introduction of flipped classroom delivery, however there was a significant increase $(p<0.0001)$ in 2016 and a further significant increase in 2017 when compared to 2015 results in response to the refinement of active learning approaches. Physiotherapy theory examination marks did not change in the first year of intervention when compared to 2014, however there was a significant increase $(p<0.002)$ in final marks in 2016 when compared to 2015. Sport Science theory examination marks increased in 2015 when compared to 2014 ( $p<0.0001$ ), the increases in marks were maintained in 2016 and further significantly increased $(\mathrm{p}<0.05)$ in 2017 when compared to 2015 values. 


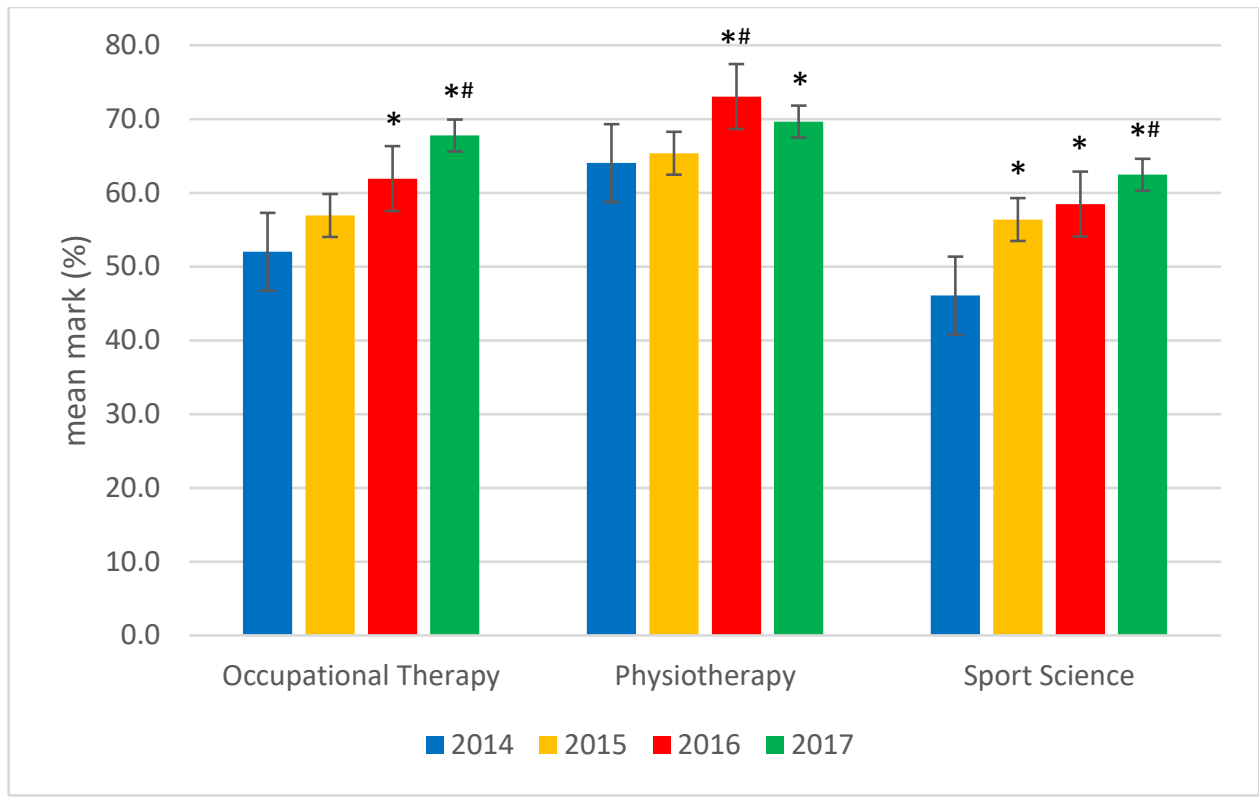

Figure 3. Theory Examination Marks

There was no change in Occupational Therapy and Physiotherapy theory examination marks in 2015 compared to 2014. Theory examination marks increased significantly in 2017 for the Occupational Therapy students and in $\mathbf{2 0 1 6}$ for the Physiotherapy students compared to 2015, with the introduction of further active learning approaches. The Sport Science marks increased in $\mathbf{2 0 1 5}$ with flipped classroom delivery with a further significant increase in marks after the introduction of active learning strategies in 2017 when compared to 2015 . $*$ p $<0.05$ when compared to 2014 values; \# $p<0.05$ when compared to 2015 values.

\section{The Final Semester Mark}

The final semester mark students obtained was an accumulation of weighted marks derived from the on course assessments (weekly tests (and DigiExplanations in 2016 and 2017)) and the practical and theory examinations. Occupational Therapy students had a highly significant improvement of $8.3 \%$ in their overall marks in 2015 ( $\mathrm{p}<0.0001$ ) compared to 2014 marks (Figure 4). The improved marks were maintained in 2016 and 2017 with the refinement of learning activities. There was no change in Physiotherapy overall mark in 2015 compared to 2014, but there was a significant increase $(\mathrm{p}<0.05)$ in overall mark in $2016(\mathrm{p}<0.0001)$ when compared to 2015 results. Sport Science overall mark increased in 2015 compared to $2014(\mathrm{p}<0.0001)$ and increased further in 2016 compared to 2015 ( $\mathrm{p}<0.05)$; this increase was maintained in 2017 $(\mathrm{p}<0.05)$. 


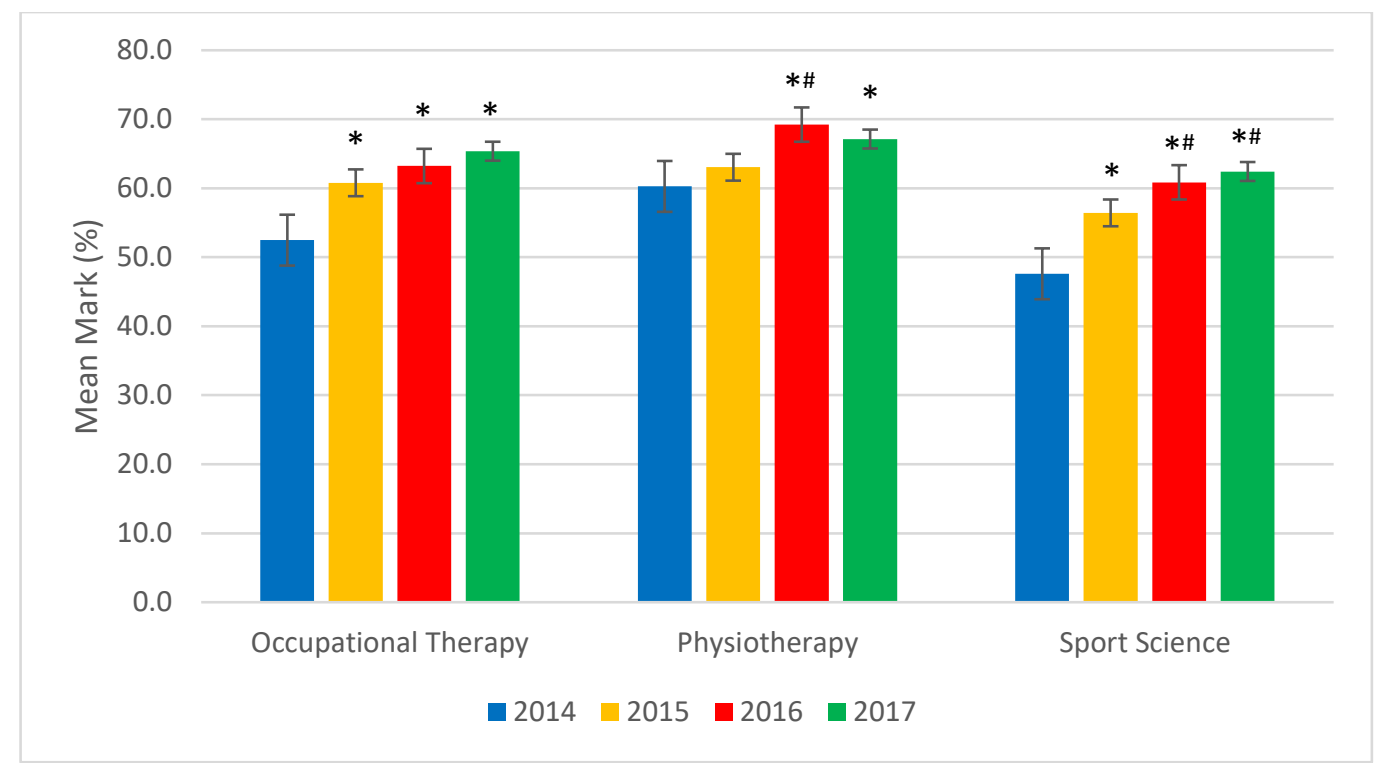

Figure 4. End of semester marks

The overall mark for Occupational Therapy and Sport Science students show improvements with the launch of the flipped classroom model, when compared to 2014 results. Introduction of further improvements to the subject by way of increasing the number of activities involving students, improved end of semester marks for Physiotherapy and Sport Science students in 2016 . * $p<0.05$ when compared to 2014 values; \# $p<0.05$ when compared to 2015 values.

\section{Final Semester Marks and Academic Preparedness}

When a CHAID test was administered to discover the relationship between the different variables in this study (entry scores, year of study, age of students), the most important factor to determine student success was student entry scores (Overall Position (OP)) scores; where a score of OP 1 is equivalent to Australia Tertiary Admission Rank (ATAR) score of 99.00+ and indicates high achievement at high school and hence preparedness for tertiary study. We classified our students into 4 OP categories: 1 to 5 (most prepared students), 6 to 10, 11 to 15 and 16+ (least prepared students) and compared final marks between the different years of the study (Figure 5).

In the first year of introduction of the flipped classroom, no change was seen in marks of the students that entered university with the highest entry scores. Significant improvement was observed in the second and third year of intervention $(\mathrm{p}<0.05)$, with overall gains of 10 percentage points between 2014 and 2017. The students in the 6 to 10 OP range showed a significant increase $(\mathrm{p}<0.05)$ in their final marks in 2015 when compared to 2014, with a further significant increase $(p<0.05)$ in results in 2016 when compared to 2015. These improvements were maintained in 2017. These gains were in the order of 10.6 percentage points higher in 2017 when compared to 2014 results. The students in OP classes 11 to 15 and 16+ improved significantly in 2015 ( $p<0.05$ ). The gains seen in 2015 were maintained in 2016 and 2017. While the students in the 11 to 15 OP range improved by 10 percentage point between 2014 and 2017, the improvements in the students with the lowest entry scores (OP range 16+) achieved gains of 14.6 percentage points in total over the course of the study. 


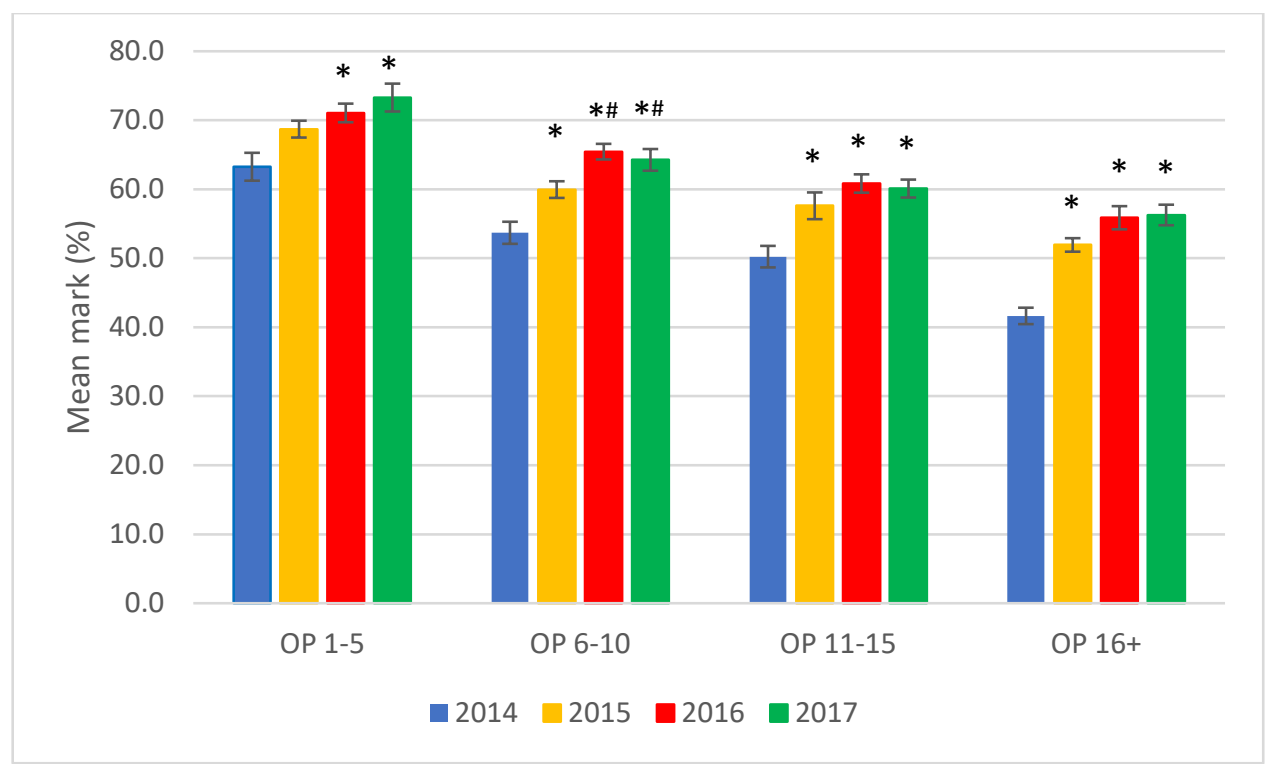

Figure 5. OP scores and final outcomes

End of semester marks achieved by the 4 OP classes 1-5, 6-10, 11-15 and 16+ pre-intervention (2014), the year of introduction (2015) and a subsequent two years of implementation of active learning approaches. * signifies significant differences $(p<0.05)$ when compared to 2014 data; signifies significant differences $(p<0.05)$ when compared to 2015 data.

A further finding from the CHAID analysis, was that after OP Scores, the second factor that determined student success in our Anatomy and Physiology subject was the year of study, with 2017 in each case found to be a strong predictor of final student results. Indeed as Figure 5 shows, results in 2017 were more favourable than the preceding 2 years, when compared to end of semester results pre-intervention.

\section{Discussion}

Previous studies have shown varying outcomes with a flipped classroom pedagogy, with improvement of results shown by McLaughlin et al., (2014) and Gopalan (2019), no changes to students' learning were observed by Jensen, Kummer \& Godoy (2015) and Ziegelmeier and Topaz (2015) and poorer student outcomes were seen by Good (2016). With the exception of the Physiotherapy students, student success, as measured by academic performance, was demonstrably increased in the first year of the intervention in this study and further gains were observed in subsequent years of active learning delivery (Figure 4). The academic gains between 2014 and 2017 for overall marks were greatest in the cohorts with the broadest range of entry scores (Occupational Therapy and Sport Science; $12.9 \%$ and 14.8\% respectively; Figure 4), for whom these changes were strategically implemented in order to improve the low rate of success. The gains of the students that entered with higher and tighter entry scores were modest (Physiotherapy; 6.9\% increase; Figure 4). We were mindful that the introduction of a flipped classroom delivery may be beneficial for the cohorts with the broadest range of entry scores, but detrimental to the more academically able students. Indeed, a change to the learning environment may have an unpredictable effect on how students approach their learning (Nijhuis, Segers \& Gijselaers, 2005). We are pleased to report that all students benefited from active learning strategies as evidenced by improved outcomes by all student groups in their end of semester marks. 
The observed gains could be attributed to a number of factors. As explained by Cavanagh (2011), Freeman et al (2014) and Jensen, Kummer \& Godoy (2015), active learning strategies improve academic performance, which was certainly the finding of this study. In this case, introduction of more active practical classes and workshops, providing guidance and scaffolding for online activities and finally, changes to assessments are believed to have contributed to improved student outcomes. Improved student outcomes for foundation sciences are of paramount importance to the professional programmes that they contribute to, as these students can progress with a solid basis to successive years of their respective degrees.

Students with low entry scores may lack the discipline and skills required to study effectively. Weekly summative assessment, we argued, should increase the students' motivation for engagement with the weekly materials delivered (Gibbs, 1999), although the authors recognise literature to the contrary (Agyei \& Mensah, 2018). The weekly test results showed an increase of $8.2 \%$ for Occupational Therapy $10.5 \%$ for Physiotherapy and $7.8 \%$ for Sport Science students in marks post-intervention, when compared to the pre-intervention results (Figure 1). Improved results were maintained in all years of delivery of our active learning approach. It must be emphasised that the tests administered in 2014 were divided, according to topics, into weekly tests so year to year the questions were very similar to ensure that the test results from one year to the next were comparable. Because these occurred at the end of a related learning session each week, it is likely that students' performances in these tests were better as a result of it being "fresh in their minds", but it is also important for retrieval practice (Weinstein, Madan and Sumeracki, 2018). Retrieval practice improves memory of the information being tested.

At the end of semester, practical and theory examinations were administered to students. Occupational Therapy practical examination marks were significantly improved after introduction of active learning strategies in 2015, however, this improvement was not seen in subsequent years (Figure 2). Sport Science students' practical examination marks were significantly improved after introduction of active learning strategies, and were sustained over the period of our study. The Physiotherapy students' practical examination marks were not significantly different in 2015 , and dropped in the second and third year of delivery, with a total overall statistically significant reduction of $9.4 \%$ over the duration of the study.

The decline in performance for the Physiotherapy students in this assessment piece was unexpected. Our change in delivery of the practical component to a station-based practical, was designed to ensure all students had the opportunity to engage with all of the learning resources available. Perhaps students were forced to spend the same amount of time on specimens and content with which they were confident, at the expense of spending more time on content that they needed to spend more time on, or revisit? Feedback from a Physiotherapy student at the end of the first year of intervention that

"The timed station for practical were helpful to make sure we covered most things, however some stations needed more time than others and there was no opportunity to go over it again"

suggests that this is a possibility. Several other Physiotherapy students provided similar feedback, which prompted us to abandon the station-based anatomy practical classes in 2016 and 2017 for the Physiotherapy cohort. With only positive feedback from the other two cohorts, station-based anatomy practical classes remained for OTs and Sports Science students. As the Physiotherapy students are high achievers, they worked quite confidently left to their own devices, however, their marks for the practical examination did not recover. On the contrary, 
they dropped further compared to the pre-intervention values. We observe a subtle difference in student behaviour, attitudes and performance from year to year, which we call a "cohort effect", but to have 3 student cohorts perform less well than expected year after year is highly unlikely to be due to this effect. It is however possible that the 2014 student cohort was atypically high achievers. Further, investigations into this cohort reveal that the end of semester results in 2013 were lower than in 2014. The 2013 results were similar to that seen in 2015 to 2017, suggesting that the 2014 results are outliers and all results presented in this study were unchanged as a result of our interventions.

Similar to the weekly tests, the questions on the practical and theory examinations from one year to the next were very similar and so comparable. Theory examination marks continuously improved with each year of delivery, with an overall improvement of the Sports Science students and Occupational Therapy students between 2014 and 2017 (Figure 3). The Physiotherapy students also demonstrated improved performance with a more modest increase over the course of the study.

When considering the overall mark for each student and correlating it to their entry score, our study showed that students with low OP scores (high ATAR scores; high achieving students) achieved higher marks than students with high OP scores. This was expected, as it is well documented that a strong positive correlation exists between university entry scores, which infer preparedness for study at a tertiary level, and actual results achieved (van Rooyen, Dixon, Dixon \& Wells, 2006; van Herpen, Meeuwisse, Hofman, Severiens \& Arends 2017; Robbins, Lauver, Le, Davis, Langley \& Carlstrom, 2004). After introduction of active learning strategies, the outcomes of students who entered university with an OP of 1 to 5 improved marginally, but the outcomes of the students that entered with higher OP marks (lower ATAR scores) improved considerably over the course of the study. This indicates that less-well prepared students made greater gains in performance with increased active involvement, when compared to students better prepared for university study. Indeed, Rathner and Byrnes (2014) showed in their study that weaker students who worked in a strong team performed significantly better. With increased student engagement in practical classes and workshops involving team-based, active learning strategies, are likely to be responsible for better student outcomes in this study.

Students who function at a high level also show high levels of engagement, which is associated with deeper learning. This group of students tend to succeed irrespective of the method of teaching employed by academic staff, as evidenced by higher overall marks in this student group in all years of our study. Students that usually perform at low levels of engagement tend to be superficial learners relying on memorisation and rote-learning (Biggs, 1999). We can propose from the results of this study that the learning behaviours of the less-well-prepared students are becoming more like those of their well-prepared counterparts. Transitioning their learning style from passive, superficial learning to a more active, deeper level learning, elevated the performance of the students with lower OP university entry scores.

We can confirm that active learning strategies implemented in our first year Anatomy and Physiology subject to allied health students reduced the gap between the non-academic and academic student outcomes. We would recommend the introduction of explicit active learning strategies into subjects that could benefit from improved student outcomes. 


\section{Acknowledgements}

We would like to thank Dr Kathryn Meldrum for her guidance and support with flipped classroom design and implementation.

We would like to thank Dr Lisa Chilton for her kind assistance with preparation of this manuscript and the reviewers for their suggestions.

\section{References}

Agyei, D. D., \& Mensah, F. S., (2018). Mathematics learning through classroom assessment: Evaluating the value of weekly class tests. African Journal of Educational Studies in Mathematics and Sciences, 14, 125138.

Biggs, J., (1999). What the Student Does: teaching for enhanced learning, Higher Education Research \& Development, 18(1), 57-75.

Bybee, R.W., Taylor, J.A., Gardner, A., Van Scotter, P., Carlson Powell, J., Westbrook, A., \& Landes, N., (2006). BSCS 5E instructional model: Origins and effectiveness. A report prepared for the Office of Science Education, National Institutes of Health. Colorado Springs, CO: BSCS.

Cavanagh, M., (2011). Students' experiences of active engagement through cooperative learning activities in lectures, Active Learning in Higher Education, 12(1), 23-33.

Freeman, S., Eddy, S. L., McDonough, M., Smith, M. K., Okoroafor, N., Jordt ,H. \& Wenderoth, M. P. (2014). Active learning increases student performance in science, engineering, and mathematics. Proceedings of the National Academy of Science, 111(23), 8410-8415.

Gibbs, G., (1999). Using assessment strategies to change the ways that students learn, pp 44-54, in: Brown, S., \& Glasner, A., (Eds) Assessment Issue three January 2002 Matters in Higher Education: Choosing and Using Diverse Approaches. Buckingham, SRHE \& Open University Press, 210.

Good, L., (2016). Implementation of Flipped Classrooms in a Non-Major Biology Course. Murray State Theses and Dissertations. 62. Retrieved July 23, 2019, from https://pdfs.semanticscholar.org/4c39/4e6b1d3913540088301dd486edb2785e6a09.pdf

Gopalan, C., (2019). Effect of flipped teaching on student performance and perceptions in an Introductory Physiology course. Advanced Physiology Education 43, 28-33.

Hoban, G., Nielsen, W., \& Shepherd, A., (2013). Explaining and communicating science using student-created blended media [online]. Teaching Science, 59(1), 32-35.

Jensen, J. L., Kummer, T. A., \& Godoy, P. D. 2015). Improvements from a flipped classroom may simply be the fruits of active learning. CBE-Life Sciences Education, 14, 1-12.

Kift, S., Nelson, K., \& Clarke, J., (2010) Transition pedagogy: A third generation approach to FYE - A case study of policy and practice for the higher education sector. The International Journal of the First Year in Higher Education, 1(1), 1-20.

McLaughlin, J. E., Roth, M. T., Glatt, D. M., Gharkholonarehe, N., Davidson, C., Griffin, L. M., Esserman, D. A. \& Mumper, R. J. (2014). The flipped classroom: A course redesign to foster learning and engagement in a health professions school. Academic Medicine, 89(2), 236-243.

Megaw, P.L. and Zimanyi, M.A. (2019). Redesigning First Year Anatomy and Physiology Subjects for Allied Health Students: Introducing Active Learning Experiences for Physiology in a First Semester Subject. International Journal of Innovation in Science and Mathematics Education, 27(8), 26-35.

Nijhuis, J. F. H. Segers, M. S. R., \& Gijselaers, W.H., (2005). Influence of redesigning a learning environment on student perceptions and learning strategies. Learning environments research. 8, 67-93.

Prince, M. (2004). Does Active Learning Work? A Review of the Research. Journal of Engineering Education 93(3) 223-231.

Ramsden (1985) Higher Education Research and Development, 4:1, 51-69.

Rathner, J.A. and Byrnes, G. (2014). The use of team-based, guided inquiry learning to overcome educational disadvantages in learning human physiology: a structural equation model. Advances in Physiology Education 38: 221-228.

Robbins, S. B., Lauver, K., Le, H., Davis, D., Langley, R., \& Carlstrom, A. (2004). Do psychosocial and study skill factors predict college outcomes? A meta-analysis. Psychological Bulletin, 130, 261-288.

Upcraft, M. L., Gardner, J. N., \& Barefoot, B. O., (2005). Challenging and supporting the first-year student: A handbook for improving the first year of college. San Francisco, CA: Jossey-Bass.

van Herpen, S. G. A., Meeuwisse, M., Hofman, A. W. H., Severiens, S. E., \& Arends, L. R. (2017) Early predictors of first-year academic success at university: pre-university effort, pre-university self-efficacy, and pre-university reasons for attending university. Educational Research and Evaluation, 23(1-2), 52-72. 
van Rooyen, P., Dixon, A., Dixon, G., Wells, G., (2006). Entry criteria as predictor of performance in an undergraduate nursing degree programme. Nurse Education Today 26, 593-600.

Weinstein, Y., Madan, C. R. and Sumeracki, M.A. (2018). Teaching the science of learning. Cognitive Research: Principles and Implications, 3(2), 1-17.

Ziegelmeier, L. B., \& Topaz, C. M., (2015). Flipped Calculus: A study of student performance and perceptions. Problems, Resources, and Issues in Mathematics Undergraduate Studies, 25(9-10), 847-860. 